\title{
Der Mantel des Königs Zum symbolischen Gehalt von Ottokars Prunkmantel in Franz Grillparzers Trauerspiel ,König Ottokars Glück und Ende‘
}

\author{
Miroslav URBANEC
}

\begin{abstract}
Abstrakt
The King's coat: on the symbolism of Ottokar's ceremonial coat in Franz Grillparzer's tragedy 'König Ottokars Glück und Ende'

Clothing plays an important role in the tragedy 'König Ottokars Glück und Ende' by the Austrian dramatist Franz Grillparzer - however, this role has not yet been adequately explored. Coats, jackets, helmets and garters are not mere props in the play; sometimes they are elevated to the level of symbols which can (and indeed must) be interpreted. Two types of garment play a particularly important symbolic role: Emperor Rudolf's grey jacket (jerkin) and King Ottokar's gold-embroidered coat. The King's coat is a symbol of his power and authority, yet it also evokes his alienation from his Bohemian subjects. It can also be interpreted as an allusion to the French Emperor Napoleon, whose features are clearly transferred into the figure of Ottokar.
\end{abstract}

Keywords: Franz Grillparzer, 'König Ottokars Glück und Ende', coat, symbol, Napoleon

DOI: doi.org/10.15452/StudiaGermanistica.2020.27.0008

\section{Symbolisches Potenzial der Kleidungsstücke im ,König Ottokar‘}

In seiner Inszenierung des Trauerspiels ,König Ottokars Glück und Ende‘, die 2005 über die Bühne der Salzburger Festspiele und des Wiener Burgtheaters ging, brachte der Regisseur Martin Kušej eine originelle Sicht auf dieses berühmte, aber umstrittene Grillparzer-Stück. „,Vor allem mit der gängigen Rolleninterpretation, der Gegenüberstellung von Ottokar als personifizierter diktatorischer Machtanmaßung und Rudolf als ordnungsstiftender Autorität , aus humanistischem, das Individuum achtendem Verantwortungsbewusstsein“ wurde gebrochen [...].“ (Großegger 2014:14) Der Regisseur brach aber nicht mit dem äußeren Kontrast der beiden Antagonisten, indem er Ottokar in einem historisierenden, kostümhaft wirkenden purpurnen Mantel und Rudolf in einem zeitgenössischen, sachlich wirkenden grauen Anzug auftreten ließ. Er strich dadurch nicht nur die kontrastierenden Charaktere von Ottokar und Rudolf heraus (ein anmaßender, theatralischer Tyrann hier, ein kalt kalkulierender, äußerlich unscheinbarer Bürokrat dort), sondern auch die kontrastierenden Epochen, für welche die beiden Monarchen stehen. Die historisierende Kostümierung des böhmischen Königs, die von einem archaisierenden Bühnenbild ergänzt wird (vgl. Großegger 2014:14), lässt Ottokar als ein unzeitgemäßes Relikt längst vergangener Zeiten erscheinen, als solches er in der Tat 
von Grillparzer konzipiert wurde. ${ }^{1}$ Dagegen macht der moderne Anzug aus dem Kaiser (historisch korrekt: König) die Inkarnation jener neuen Zeit, als deren Stifter sich Rudolf vor Ottokar präsentiert und deren Deutung in der Grillparzer-Forschung bis heute kontrovers diskutiert wird. ${ }^{2}$ Durch die sorgfältig getroffene Wahl der von Ottokar und Rudolf getragenen Kleidungsstücke macht Kušej deutlich, dass er sie als genau das versteht, was sie in der Tat sind: Symbole.

Grillparzers Spiel mit den Symbolen wurde schon mehrmals untersucht. Renate Deplhendahl z. B. meint, dass Grillparzers Gesamtwerk voller (Sinn-) Bilder ist: „Grillparzer spricht in Gleichnissen und Bildern“ (Delphendahl 1975:104). Und weiter, in Anlehnung an Grillparzers Tagebücher: „Grillparzers Dichtung gewinnt ihre Überzeugungskraft aus dem Nebeneinander von Wort und Bild. [...] Im Mittelpunkt von Grillparzers Schaffen stehen ,Wort und Bild zu gleicher Zeit ‘[...]" (Ebenda:109 f.). Eda Sagarra, die Grillparzers ,König Ottokar' mit Shakespeares ,Richard II.' vergleicht, spricht zwar vorsichtiger als Delphendahl, aber auch sie bescheinigt Grillparzer einen dramaturgisch durchdachten Einsatz von Bildern: „Grillparzer macht einen viel spärlicheren Gebrauch von bildlicher Sprache als Shakespeare. Aber die wenigen Bilder, deren er sich bedient, sind strukturell und thematisch von zentraler Bedeutung [...]" (Sagarra 1986:60). Beide Forscherinnen deuten vor allem bestimmte Kleidungsstücke als wichtige Symbole: Delphendahl den Mantel, den sie als ,eines der Lieblingsrequisiten in Grillparzers Dramen“ (Delphendahl 1975:113) bezeichnet und dessen Bedeutung sie in Grillparzers Gesamtwerk untersucht; Sagarra den Mantel, den Helm und die aus diesem Helm hervorgegangene Krone, in denen sie die Symbole des Herrscheramtes sieht und die „Träger der Handlung im Ottokar" (Sagarra 1986:60) erkennen will. Hinzufügen könnte man den grauen Rock des Kaisers, der sozusagen sein „Markenzeichen“ ist ${ }^{3}$ und auf den auch der Bilderstürmer Kušej nicht verzichten wollte (auch wenn er aus ihm einen grauen Anzug gemacht hat), und die rot-weiße Ärmelschleife der Königin Kunigunde, die Grillparzer dramaturgisch geschickt in die Anbahnung der Komplizenschaft zwischen Kunigunde und Zawisch eingebunden hat. ${ }^{4}$ Vor allem den beiden oben erwähnten Kleidungsstücken fällt eine wichtige Rolle zu: dem goldgestickten Mantel des böhmischen Königs und dem grauen Rock des Kaisers. Letzterer kann als ein Requisit einer geheuchelten Bescheidenheit nach Art der modernen Populisten gedeutet werden (vgl. Lorenz 1986:126-127). In Anbetracht der romantischen Deutschtümelei, aus der sich Grillparzers ,König Ottokar' ideell speist, ${ }^{5}$ kann der graue Rock aber auch als eine poetische Überhöhung der als „De-

\footnotetext{
Jürgen Kost meint in Anlehnung an Grillparzers Tagebuchnotizen, dass Grillparzer die Aufgabe eines historischen Dramas in der Offenlegung der historischen Notwendigkeit gesehen hat: „Genau das leistet König Ottokar, indem das Drama in Ottokar und Rudolf die Vertreter zweier Epochen im Augenblick der Zeitenwende, der Epochenschwelle miteinander konfrontiert: Zwei eigentlich aufeinanderfolgende Epochen werden gleichzeitig auf die Bühne gebracht, und Ottokar wird - gemessen am Prinzip der historischen Notwendigkeit - zum Repräsentanten der untergehenden, der archaischen Ordnung, zum Anachronismus“ (Kost 2002:137 f.).
}

2 Der Kaiser sagt wörtlich: Nicht Völker stürzen sich wie Berglawinen / Auf Völker mehr, die Gärung scheidet sich, / Und nach den Zeichen sollt es fast mich dünken / Wir stehn am Eingang einer neuen Zeit. / Der Bauer folgt in Frieden seinem Pflug, / Es rührt sich in der Stadt der fleißge Bürger, / Gewerb und Innung hebt das Haupt empor, / In Schwaben, in der Schweiz denkt man auf Bünde, / Und raschen Schiffes strebt die muntre Hansa / Nach Nord und Ost um Handel und Gewinn. (KO: 466) An der Deutung dieser Worte scheiden sich die Geister. Während Alfred Doppler in Rudolfs Vision eine ,josephinisch-bürgerliche Tendenz“ sehen will (Doppler 1990:19), sieht Jürgen Kost in der von Rudolf wiederhergestellten Ordnung, die die Voraussetzung für die ,neue Zeit“ ist, ,ganz deutlich eine Feudalordnung, eine Lehnsordnung“ (Kost 2002:136).

3 Im dritten Aufzug, unmittelbar vor der Begegnung der beiden Antagonisten auf der Insel Kaumberg, schildert der Kanzler Braun von Olmütz dem böhmischen König den Jubel, der dem neuen Kaiser überall entgegenweht: Als er auf der Donau nur allsamt dem Heer / Nach Wien er niederfuhr mit lautem Schall, / Da tönte Glockenklang von Beiden Ufern, / Von Beiden Ufern tönte Jubelruf, / Der Menge, die dort kam und staunt' und kniete, / Wie sie den Kaiser sahn im grauen Röcklein [Hervorhebung M.U.] / Am Vorderteil des Schiffes stehn allein / Und freundlich grüßend mit des Hauptes Neigen (KO:451 f.).

4 Eine aufschlussreiche Analyse des Spiels mit der Schleife, dem „Erzfetisch der deutschen Literatur, mit dem noch Thomas Mann die erotischen Fäden knüpfen wird“, findet man in Prutti (2013:337 ff.) (Zitat aus der Seite 337).

5 In seiner aufschlussreichen Studie ,Zwischen Napoleon, Metternich und habsburgischem Mythos` legt Jürgen Kost überzeugend dar, wie tief Grillparzer noch zu Beginn der 1820er Jahre - also zu der Zeit, als er an seinem ,König Ottokar 
magogenkleidung“ diffamierten „Altdeutschen Tracht“ der deutschnational gesinnten Burschenschafter und somit als ein Symbol von Rudolfs deutschnationaler Gesinnung gedeutet werden (vgl. Urbanec 2019:66 ff.). Es bleibt die Frage, ob der Prunkmantel des böhmischen Königs ebenfalls eine Anspielung auf ein real existierendes Kleidungsstück ist.

\section{Symbolisches Potenzial des Mantels im ,König Ottokar}

Im ,König Ottokar‘ gibt es insgesamt vier Figuren, die in einem Mantel auftreten: Ottokar selbst, seine erste Frau Margarethe, seine zweite Frau Kunigunde und sein Heerführer Milota. Während Milotas Mantel ein Requisit ohne einen symbolischen Wert sein dürfte (er wird in einer Regieanweisung im fünften Aufzug erwähnt, als Milota dem von Seyfried bedrängten König die Hilfe verweigert und, ohne sich um ihn zu kümmern, nach Hause geht - vgl. KO:506), ist es im Fall der Mäntel, in denen die beiden Königinnen (wohlgemerkt: zum gleichen Zeitpunkt) auf der Bühne erscheinen, anders. Als Margarethe zum zweiten Mal (nach einer kurzen Unterredung mit dem Noch-Grafen Rudolf) die Bühne betritt, um offiziell über die Scheidung von Ottokar informiert zu werden und die Schenkung ihrer Erbländer an den nunmehrigen Ex-Gatten zu wiederholen, trägt sie - so die Regieanweisung - einen „,nachschleppenden Mantel“ (vgl. KO:412). Dieser soll sie - zusammen mit der Krone, die ihr laut gleicher Regieanweisung auf dem Haupt sitzt - als die wahre Königin erscheinen lassen, als welche sie von den österreichischen und steirischen Ständen sofort anerkannt wird. ${ }^{6}$ Der Mantel funktioniert hier - ähnlich wie bei Ottokar - als ein Symbol der königlichen Würde bzw. der herrscherlichen Macht. Bei Kunigunde hat der Mantel - hier kein Königs-, sondern ein Reitermantel, wie er von ungarischen Kriegern getragen wird - ebenfalls einen hohen symbolischen Wert. Er streicht die kriegerische Natur der neuen Königin heraus ${ }^{7}$ und lässt sie - zusammen mit dem „ungarischen Kalpak“, den sie auf dem Haupt trägt (vgl. KO:419) - als die „Metonymie [ihres von Ottokar] besiegten Landes“ erscheinen (vgl. Prutti 2013:328 f. sowie Delphendahl 1975:110). Der König schließlich hüllt sich im Laufe des Trauerspiels in zwei Mäntel: den goldgestickten Mantel eines Herrschers und den dunklen Mantel eines Namenlosen.

Ottokars Prunkmantel taucht zum ersten Mal im ersten Aufzug auf. Der triumphierende König kehrt aus dem Krieg gegen die Ungarn heim und betritt - ganz in Rüstung gekleidet - den Thronsaal auf der Prager Burg, in dem sich ,böhmische Große und Krieger“ (KO:406, Regieanweisung) versammelt haben. Im martialischen Erscheinungsbild des Königs wird das Bild des Kriegsgottes Mars wieder lebendig, das Grillparzer auf dem Titelblatt der Chronik ,Mars Moravicus` von Tomáš Pešina von Čechorod gefunden hatte und dem er rückblickend eine Schlüsselrolle bei der Entstehung des ,König Ottokar` zuschrieb:

„Ich darf des Anteils nicht vergessen, den ein Mars Moravicus in folio, den ich mir als Quelle für den Ottokar beigelegt, auf das Zustandekommen jenes Durchbruchs allerdings genommen hat. Auf dem Titelblatte dieses Mährischen Mars war nämlich der Kriegsgott in voller Rüstung ungefähr so abgebildet wie ich mir die äußere Erscheinung Ottokars gedacht hatte. Diese Figur reizte mich an, meine Gestalten nach auswärts zu werfen, und auch während der Arbeit kehrte ich jedesmal zu ihr zurück, sooft sich meine Bilder zu schwächen schienen.“ (Zitiert nach Pörnbacher 1970:62)

Unmittelbar nach seiner Ankunft entledigt sich Ottokar der Rüstung und hüllt sich in einen Prunkmantel, in dem sich seine herrscherliche Macht verdichtet. Das symbolische Potenzial dieses

arbeitete - an der von Romantikern formulierten, von dem Nationalismus der Befreiungskriege gekennzeichneten frühen Form des habsburgischen Mythos verbunden war: „Es gibt wenig Grund daran zu zweifeln, dass Franz Grillparzer um 1820 politisch-weltanschaulich den Positionen Friedrich Schlegels und Adam Müllers nahestand, jenen Vertretern des sich entwickelnden habsburgischen Mythos in seiner radikalsten Form“ (Kost 2002:150).

6 Der Wortführer der österreichischen Stände wendet sich mit seiner Huldigung vornehmlich an Margarethe (vgl. KO:413), der Wortführer der steirischen Stände kniet vor ihr, nicht vor Ottokar, nieder (vgl. KO:416).

7 Als Kunigunde, die in ihrer Aufmachung wie ein Mann aussieht und ihren werdenden Gatten fragt, ob er sie unter seine Krieger aufnehme, die Bühne betritt, ruft Zawisch aus: O schöner Krieger! (KO:419) 
Kleidungsstücks ist damit aber noch nicht erschöpft. Der Prunkmantel ist in dieser Szene nicht nur das Symbol der königlichen Würde, sondern auch das Symbol der vom König betriebenen Kolonisationspolitik, die den Reichtum seines Königreiches mehren soll, wegen ihrer Rücksichtslosigkeit aber bei den Böhmen (Tschechen) auf Ablehnung stößt. In seiner Antwort an den Prager Bürgermeister, der vorsichtig gegen die Vertreibung der „treuen Böhmen“ aus der Prager Vorstadt zu protestieren versucht (vgl. KO:409 f.), redet sich Ottokar in Rage, verwirft die traditionelle Lebensweise seiner böhmischen Untertanen und erklärt sich - unter einem eindeutigen Hinweis auf den ihn umhüllenden, in Deutschland gekauften Mantel - zum Anwalt des Fortschritts:

\begin{abstract}
Ich weiß wohl was ihr mögt, ihr alten Böhmen: / Gekauert sitzen in verjährtem Wust, / Wo kaum das Licht durch blinde Scheiben dringt; / Verzehren was der vorge Tag gebracht, / Und ernten was der nächste soll verzehren, / Am Sonntag Schmaus, am Kirmes plumpen Tanz, / Für alles andre taub und blind; / So möchtet ihr, ich aber mag nicht so! [...] Sehr her! / Der Mantel ward in Augsburg eingekauft. / Das Gold, der Samt, die Stickerei, das Ganze, / Könnt ihr das machen hier in eurem Land? I Ihr sollt! Bei Gott, ihr sollt! Ich will euchs lehren! (KO:410)
\end{abstract}

Somit verdinglichen sich in Ottokars Prunkmantel auch die Geringschätzung, die der König für die angeblich kulturlosen Böhmen empfindet, und die mit Neid gepaarte Bewunderung, mit der er die Kulturleistungen der Deutschen betrachtet. Dass er dadurch die Bande zum eigenen Volk zerstört, mit dessen Blut er zugegebenermaßen seine Eroberungen bezahlt hat (vgl. KO:444), nimmt er nicht wahr.

Im ersten Aufzug erscheint Ottokar auf der Höhe der Macht und des Tatendrangs. Außer, dass er die Grundzüge seiner Innenpolitik formuliert, ordnet er die Gründung einer Stadt an, die an den Sieg gegen die Ungarn erinnern soll, und ordnet auch seine Familienverhältnisse neu (die Scheidung von Margarethe, die Heirat mit Kunigunde). In dieser Szene wird nicht nur der Kriegsgott Mars aus Pešinas Chronik wieder lebendig, sondern auch jener Napoleon, von dem Grillparzer in seinem Tagebuch schreibt: Fürchterlich ist schon bei seinem ersten Auftreten die Art wie Napoleon überall nichts sieht als seine Ideen und bereit ist ihnen alles aufzuopfern (Zitiert nach Pörnbacher 1970:63; vgl. auch Doppler 1990:34). Einen Kontrapunkt zu dieser Szene bildet die Anfangsszene im vierten Aufzug: Der gedemütigte König kehrt aus dem Krieg gegen den Kaiser heim, will aber die Prager Burg nicht betreten, sondern er bleibt - in einen dunklen Mantel gehüllt - vor einem Ausfallstor sitzen. Da gehen an ihm die gleichen Bürger vorbei, die er im ersten Aufzug mit seinem Prunkmantel beeindrucken wollte, und der gleiche Bürgermeister, dem er einst im barschen Kommandoton Befehle gegeben hat, verwechselt ihn nun mit einem ,abgedankten Söldner“ (KO:472). Auch Kunigunde, Zawisch und die Rosenberge, die hier für die „böhmischen Großen und Krieger“ stehen, sind anwesend und runden mit ihren Schmähungen das Bild eines grotesk umgekehrten Huldigungsaufmarsches ab. Symbol von Ottokars Fall (und dessen möglicher innerer Umkehr - vgl. Delphendahl 1975:116 f.) ist der dunkle Mantel, den er anhat und der mit dem verlorenen Prunkmantel kontrastiert.

Ottokar verliert seinen Prunkmantel am Ende des dritten Aufzugs, wenn er die Bühne fluchtartig verlässt. Dieser fast schon komischen Flucht, die einen grellen Kontrast zu seiner pompösen Ankunft bildet, geht der Eklat bei der Belehnung des Königs mit Böhmen und Mähren voraus. Nachdem er die Ausweglosigkeit seiner militärischen sowie politischen Lage eingesehen hat, erklärt sich Ottokar einverstanden, seine Länder vom Kaiser als Lehen zu empfangen, und begibt sich mit Rudolf in ein Zelt. Die schützende Zeltwand ist notwendig, denn es werden / Des Reiches Lehen knieend nur genommen (KO:467) Da kommt Zawisch, der dem König die Verwerfung der von den Rosenbergen eingefädelten Heirat mit der Rosenbergerin Berta nicht verziehen hat, und durchtrennt mit seinem Schwert die Zeltschnüre. Die Absicht des Rosenbergs ist klar: Er will den einst so gefürchteten Herrscher und Heerführer dem Hohn seiner Untertanen und Soldaten preisgeben, indem er ihn - geschmückt mit den früher so stolz zur Schau gestellten Insignien seiner Autorität (Krone, Prunkmantel) - auf den Knien vor dem Mann zeigt, für den er bis dahin nur Worte der Abwertung hatte. Das Kalkül des Rosenbergs geht auf, zumal Ottokar nach dem sofortigen Aufspringen zum 
zweiten Mal vor Rudolf niederknien muss, um nach Böhmen auch mit seinem zweiten Land, Mähren, belehnt zu werden. Wenn er schließlich - nach dem Abgang des Kaisers für einen Moment in tiefer Scham verharrend - von seinem früheren Bewunderer Seyfried angesprochen wird, der für seinen eingekerkerten Vater bitten will, fährt [Ottokar] empor und sieht [Seyfried] mit einem grimmigen Blicke an; dann zerreißt er mit einer Hand die Spange des Mantels, dass er fällt; mit der andern reißt er von hinten die Krone vom Haupte, und stürzt fort, ausrufend: Fort! (KO: 468f.). In dieser kurzen, nur wenige Minuten dauernden Szene - einem kleinen, aber effektvollen Entthronungsdrama innerhalb des großen, um Ottokar und Rudolf zentrierten „Devestitur- und Investiturdramas“ (Prutti 2013:315) - wird in grotesker Umkehrung die Krönung Napoleons I. wiedergegeben.

Wie bekannt, ließ sich Napoleon - anders als sein bemühter „Vorgänger“ Karl der Große - nicht von dem Papst krönen (obwohl dieser an der Krönungszeremonie teilnahm), sondern er setzte sich am 2. Dezember 1802 die Krone selbst auf das Haupt. Die mit großer Pomp begangene Krönungszeremonie in der Pariser Notre Dame, deren Verlauf eine Synthese königlicher Traditionen und napoleonischer Innovationen darstellte, war voller Symbole, die eine Kontinuität zwischen dem neugebackenen Kaiserreich und dem alten fränkischen bzw. römischen Imperium herstellen sollten. Von hohem symbolischem Wert waren vor allem zwei Krönungsinsignien: die Krone und der Purpurmantel. Die Krone, mit der sich Napoleon krönte, wurde von ihm „Krone Karls des Großen“ genannt und sollte die Kontinuität zwischen dem Kaiser der Franzosen und dem Kaiser der Franken bzw. Römer herstellen. Der monumentale, mit goldgestickten Bienen besäte Purpurmantel, in den sich Napoleon während der Krönungszeremonie hüllte, sollte wiederum die Kontinuität zwischen der napoleonischen Dynastie und den Merowingern herstellen. ${ }^{8}$ Wenn sich nun Grillparzers Ottokar die Krone vom Haupt reißt, den Prunkmantel fallen lässt und eiligst von der Bühne verschwindet, dann kann diese Szene sehr wohl als ein Zerrbild von Napoleons Selbstkrönung interpretiert werden, die unter umgekehrtem Vorzeichen (Devestitur statt Investitur, Demütigung statt Huldigung, Flucht statt Triumph) stattfindet. ${ }^{9}$

Die Anspielung auf Napoleons Selbstkrönung ist nicht zufällig, denn zwischen Grillparzers Ottokar und dem historischen Napoleon gibt es (von Grillparzer selbst teilweise zugegebene) Analogien. ${ }^{10}$ Grillparzers Ottokar ist ein starkes, tatkräftiges Individuum, das seine Herrschaft allein mit seinen Fähigkeiten legitimiert. Trotz seiner königlichen Herkunft und der Hilfe seines Vaters, des ,listigen“ Königs Wenzeslav, der „mit Bitten, Drohn, Versprechen und Geschenken“ die österreichischen Stände zur Wahl des böhmischen Prinzen zum österreichischen Herzog bewogen hat (KO:404), tritt Ottokar als ein dreister, aber nicht ungeschickter Emporkömmling auf, der sich die zerrütteten Verhältnisse im Reich (Interregnum) zunutze macht und sozusagen mit eigenen Händen ${ }^{11}$ ein gewaltiges Reich aufbaut. Wenn der kaiserliche Herold von ihm verlangt, die österreichischen Länder dem Reich zurückzugeben, weigert sich Ottokar dies zu tun, indem er sich auf sein und seiner Untertanen vergossenes Blut, die von ihm eingefädelten Erbverträge und die von ihm geschlossene Heirat mit der Babenbergerin Margarethe beruft: Herr, es ist aber mein! / Den Ungarn hab ich Steier abgewonnen / Mit meinem Blut, mit meiner Böhmen Blut. / Vererbt ward Kärnten

8 Das Motiv der Bienen wurde den Grabbeigaben des fränkischen Königs Childerich I. entnommen, der aus dem Geschlecht der Merowinger stammte und dessen Sohn Chlodwig I. als Begründer des Frankenreiches gilt.

9 Brigitte Prutti sieht das genauso, wenn sie in Bezug auf Ottokars Flucht von der Bühne schreibt: „Deutlich ist auch hier wieder die visuelle Anspielung auf Napoleon, der sich die Krone im Akt der Kaiserkrönung bekanntlich selbst aufgesetzt hat" (Prutti 2013:343).

10 In seiner ,Selbstbiographie“ bedauert Grillparzer die angebliche Unmöglichkeit, Napoleons ereignisreiche Vita ,poetisch“ zu behandeln, will dann aber in der „entfernten Ähnlichkeit“ des Franzosenkaisers „,mit dem Böhmenkönige Ottokar II.“ eine Rettung gefunden haben: Beide wenn auch in ungeheuerm Abstande, tatkräftige Männer, Eroberer, ohne eigentliche Bösartigkeit durch die Umstände zur Härte, wohl gar Tyrannei fortgetrieben, nach vieljährigem Glück dasselbe traurige Ende, zuletzt der Umstand, dass den Wendepunkt von beider Schicksal die Trennung ihrer ersten Ehe und eine zweite Heirat gebildet hatte (Zitiert nach Pörnbacher 1970:58 f.).

11 Die Hand-Metapher ist hier nicht unbegründet - weist doch Ottokar die Warnung seiner Frau Margarethe vor den treulosen Ständen mit den Worten zurück: Ich halte sie, sehr Ihr? mit dieser Hand; / Sie sollen sich nur regen, wenn sies wagen! (KO:415) 
mir von meinem Ohm / Durch gleicher Erbverträge Wechseltausch, / Und Östreich brachte mir zur Morgengabe / Die Königin Margrethe, meine Gattin (KO:444). Wenn er sich zu Rudolf, der diese Argumente nicht gelten lässt, begibt, um von ihm die streitigen Gebiete zu fordern, glaubt Ottokar den von ihm als Krieger, nicht aber als Kaiser geschätzten Habsburger allein durch den Kommandoton seiner Stimme in die Knie zwingen zu können:

Und wahrlich, Zawisch, sehen möcht ich ihn! / Wie er sich nimmt, dem Ottokar gegenüber, / Der arme Habsburg in dem Kaiserkleid? / Was er entgegnet, wenn im selben Ton, / Mit dem ich ihm bei Kroissenbrunn befahl: / „Herr Graf, greift an" ich Östreich nun und Steier / Und all die Lehen von dem Reich begehre? / Das hieße siegen, ohne Heer, allein! (KO:454; vgl. auch Kost 2002:130)

Jürgen Kost bezeichnet Grillparzers Ottokar, der ,seine Herrschaft aufgrund seiner eigenen Macht und Größe sichert“", der ,keinen göttlichen Willen, keine Tradition, keine Ordnung außerhalb seiner selbst als verbindlich ansieht“, und der „,die Welt nach seiner Vorstellung formen [...] will“", als ,eine prometheische Figur“ und „ein großes autonomes Individuum“ (Kost 2002:129). Er macht auf die gleichen Züge bei dem historischen Napoleon aufmerksam und identifiziert Grillparzers Böhmenkönig eindeutig als das poetische Abbild des realen Franzosenkaisers: „Beide, Ottokar wie Napoleon, repräsentieren den neuzeitlichen Individualismus und Subjektivismus, beide repräsentieren ein auf der Größe der eigenen Individualität beruhendes, letztlich modern legitimiertes Herrschertum“ (Ebenda:133).

Eine mögliche Analogie zwischen Grillparzers Ottokar und Napoleon, die von der GrillparzerForschung bisher unbeachtet gelassen wurde und bei der die Kleidung, vor allem der Mantel, eine wichtige Rolle spielt, dürfte auch jene Szene enthalten, deren spektakulären Abschluss Ottokars „Devestitur“ bildet - nämlich die Begegnung der beiden Antagonisten auf der Insel Kaumberg. Diese ergibt sich aus dem unbefriedigenden Verlauf des Kriegs, den Ottokar gegen Rudolf führt. Nachdem sich seine Hoffnungen auf einen raschen Sieg zerschlagen haben und in seinem Heerlager Hunger und Krankheiten grassieren, willigt der König nach einem gewissen Hin und Her in die Einladung des Kaisers zu einer persönlichen Unterredung ein. Im Bewusstsein seiner schwächeren Position (ZAWISCH: Die Feinde sind im Nachteil, das ist klar! / OTTOKAR: Das ist nicht klar. Die Wage steht für sie. - KO:453), aber in der Überzeugung von seiner alles entscheidenden persönlichen Überlegenheit (Der einzge Vorteil-doch der soll entscheiden! - / Ist, dass Euch Ottokar, und Jene Habsburg führt. - KO:453), entscheidet sich Ottokar für eine Wiederholung seines großen Auftritts aus dem ersten Aufzug. So, wie er die böhmischen Adeligen und die Prager Ratsherren durch seine majestätische, durch Rüstung und Mantel potenzierte Erscheinung eingeschüchtert hat, will er nun den Kaiser und dessen Truppen einschüchtern. Zu seinen Gefolgsleuten gewandt, befiehlt er: Und was sich regt im Lager, groß und klein - / [...] / Das sei bereit und rüste sich in Pracht. / Von Gold und Silber lasst die Rüstung starren; / Und weh dem Edelknecht, des Wams und Mantel / Nicht hundertmal den deutschen Kaiser aussticht (KO:455). Die Absicht, mit glänzender Rüstung und bunter Kleidung die abgemagerten Körper der hungerleidenden Böhmen zu kaschieren, wird zwar nicht ausgesprochen, versteht sich aber von selbst. Wenn der König mit seinem Gefolge schließlich dem Kaiser entgegentritt, bietet er ein Bild, in dem der Herrscher mit dem Heerführer verschmolzen ist. In der Regieanweisung steht: König Ottokar kommt in glänzender Rüstung, darüber einen bis auf die Fersen gehenden reichgestickten Mantel; statt des Helmes die Krone auf dem Haupt. Hinter ihm der Kanzler und Gefolge (KO:460). Rudolf, der sich für die gottgewollte Verkörperung des ewigen Kaiseramtes hält, ${ }^{12}$ lässt sich allerdings von dem (trügerischen, wie sich schnell zeigt) Glanz eines - wie auch immer großen - Individuums weder beeindrucken noch einschüchtern. Er kontert die Respektlosigkeit des Königs, der in ihm den kleinen Grafen von gestern sehen will, ${ }^{13}$ mit der

12 Rudolf sagt wörtlich: Ich bin nicht der, den Ihr voreinst gekannt! / Nicht Habsburg bin ich, selber Rudolf nicht; / In diesen Adern rollet Deutschlands Blut. / Und Deutschlands Pulsschlag klopft in diesem Herzen. / Was sterblich war, ich hab es ausgezogen, / Und bin der Kaiser nur, der niemals stirbt (KO:462).

13 Wenn Ottokar Rudolfs Heerlager betritt, grüßt er Rudolf nicht als den Kaiser, sondern - wie früher, als Rudolf noch in Ottokars Heer kämpfte - als den Grafen: Gott grüß Euch, Habsburg! (KO:460) 
Würde einer überindividuellen Institution, führt Ottokar die Ausweglosigkeit seiner Lage vor Augen und stempelt ihn (indirekt) ${ }^{14}$ als ein unzeitgemäßes Relikt aus längst vergangenen Zeiten ab. Der Plan des Königs, seinen ehrfurchtgebietenden Auftritt aus dem ersten Aufzug zu wiederholen und mittels der zur Schau getragenen Insignien seiner Macht über die unbefriedigenden Zustände in seinem Heer hinwegzutäuschen, schlägt fehl. Ottokar bleibt keine andere Wahl, als sich dem Unvermeidlichen zu beugen und Böhmen und Mähren vom Kaiser als Lehen anzunehmen.

In Napoleons Leben gibt es ein Ereignis, das sich zum Vergleich mit der vorbeschriebenen Szene aus dem ,König Ottokar' anbietet. Es handelt sich um das sog. Maifeld von 1815, eine Kundgebung aus der episodischen Herrschaft der Hudert Tage (Napoleons zweite Amtszeit, die mit seiner Rückkehr aus der Verbannung auf Elba einsetzt und mit seiner Abdankung nach der Niederlage bei Waterloo endet). Diese Kundgebung, bei der Napoleons Kleidung eine wichtige Rolle zugekommen ist, kann als ein fehlgeschlagener Versuch gedeutet werden, durch das demonstrative Herausstellen der Insignien der herrscherlichen Autorität über die Tatsache hinwegzutäuschen, dass dieser Autorität weitgehend der Boden entzogen worden ist. Ähnlich wie die Krönung, die eine Kontinuität zwischen Napoleon und den Karolingern und Merowingern herstellen sollte, hatte auch das Maifeld, das am 1. Juni 1815 auf dem Pariser Marsfeld stattfand, eine Kontinuität zwischen dem napoleonischen Kaisertum und dem karolingischen und merowingischen Frankenreich herzustellen. Die Maifelder (ursprünglich Märzfelder), die nach dem Monat ihrer Abhaltung benannt wurden, waren seit Chlodwig I. Versammlungen von freien Männern (später von Repräsentanten der herrschenden Schicht) gewesen, die der Herrscherhuldigung, der Heerschau und der politischen sowie militärischen Beratung gedient hatten. Napoleon griff auf diese mittelalterliche Institution zurück, um sich im Beisein politischer und militärischer Würdenträger publikumswirksam in Szene zu setzen und - über den eigentlichen Zweck der spektakulären Veranstaltung hinausgehend - ${ }^{15}$ seine prekäre Lage auszublenden. ${ }^{16}$ Darum bemühte der Kaiser die Geschichte, um sich - wie bei der Kaiserkrönung von 1804 - als der wahre Nachfolger der mittelalterlichen Herrscher Frankreichs zu präsentieren. Auch die Wahl seiner Kleidung entsprach dieser Absicht. Der offiziell konstitutionelle Monarch hatte es abgelehnt, in schlichter Uniform aufzutreten, sondern er präsentierte sich in einem herrscherlichen Kostüm, das den selbstbewussten Ton seiner Rede betonen sollte und dessen auffälligster Bestandteil der von der Krönung her bekannte, mit den Merowingischen Bienen besäte Purpurmantel war (vgl. Thiers 1865:552). Das Echo, das der Auftritt des Kaisers hervorgerufen hatte, war jedoch überwiegend negativ. Napoleon wirkte in seinem Purpurmantel unangebracht und die zur Schau gestellte kaiserliche Pomp irritierte Freund und Feind:

„Napoleon beging einen Fehler, als er, ähnlich wie seine Brüder, das Festornat anlegte, das er bei der Krönung getragen hatte. Die Menschen erwarteten den Petit Carporal aus dem ,Flug des Adlers', und sahen nur einen ,Clown'. ,Eine Maskerade', kommentierte Herzog de Broglie, , die in mir lediglich Empörung und Verachtung hervorgerufen hat‘. Es waren nicht nur die Royalisten, die sich empört zeigten. Die kaiserliche ,Pomp“ beleidigte auch die Augen, der alten Patrioten, die sich missbraucht fühlten'. Er [Napoleon - Anm. M.U.] sollte keine Erinnerungen wecken, wie es Fleury de Chaboulon sehr treffend formulierte.“ (Castelot 1998:486; Übersetzung M.U.)

Potenziert wurde diese Irritation durch den imperialen Ton der von Napoleon gehaltenen Rede: „Dass er, um seine unabhängige Autorität zu zeigen, nicht im Soldatenrock der Nationalgarde,
sondern in einem blendenden Phantasiekostüm der Majestät erschienen war, machte einen eben-
so ungünstigen Eindruck wie die Ausdrücke ,Mein Volk', ,Meine Hauptstadt' in seiner Rede. Man

14 Rudolf spricht in der 3. Person, wenn er Ottokar nahelegt, dass seine Zeit abgelaufen ist: Der Jugendtraum der Erde ist geträumt, / Und mit den Riesen, mit den Drachen ist / Der Helden, der Gewaltgen Zeit dahin (KO:466).

15 Der Kaiser sollte sich durch einen Eid auf das Evangelium zur Einhaltung der revidierten Verfassung des Kaiserreiches verpflichten und den darauffolgenden Treueschwur des Volkes entgegennehmen.

16 Ein beträchtlicher Teil der französischen Bevölkerung und sämtliche europäischen Monarchen nahmen der Wiederherstellung des napoleonischen Kaiserreiches gegenüber eine skeptische bzw. feindliche Stellung ein. 
hatte derlei von dem Sprössling der Revolution nie gerne gehört. Und vollends jetzt.“ (Fournier 1906:336 f.)

Napoleon als ein Bramarbas, der die Fragilität seiner Machtbasis mit Selbstbewusstsein und Purpur kaschieren will - ob es nicht ein Vorbild für Ottokars möchtegernmajestätischen Auftritt vor Rudolf auf Kaumberg war? Belegen kann man es nicht, denn in Grillparzers Hinterlassenschaft findet sich kein diesbezüglicher Hinweis. Aber es ist unwahrscheinlich, dass dem Dichter dieses wichtige Ereignis in Napoleons Karriere verborgen geblieben wäre. Zumal er in seiner ,Selbstbiographie' zugibt, kein Buch über den Franzosenkaiser unbeachtet gelassen zu haben: Ich hatte mit beinahe ausschließlicher Begierde alles gelesen, was über den außerordentlichen Mann von ihm selbst und von andern geschrieben worden war (zitiert nach Pörnbacher 1970:58). Die Annahme, dass Grillparzer das napoleonische Maifeld als Inspirationsquelle für die Begegnung zwischen dem angeschlagenen Böhmenkönig und dem siegessicheren Kaiser verwertet hat, erscheint auch deshalb als begründet, weil die „Devestitur“ des Böhmenkönigs, die gleich im Anschluss an die Begegnung mit dem Kaiser stattfindet, sichtbar durch die Investitur des Franzosenkaisers inspiriert wurde. Auch wenn man sich damit auf den sehr schwankenden Boden der Spekulation begibt, könnte man die Ereignisse im dritten Aufzug als ein stark komprimiertes Abbild der Herrschaft der Hundert Tage deuten: ein letztes Fest, auf dem die ehemals ehrfurchtgebietende herrscherliche Pomp zur peinlichen Maskerade wird, die demütigende Niederlage durch die Hand eines unterschätzten, jedoch militärisch und ideell überlegenen Gegners, Verlust des Ansehens bei dem eigenen Gefolge, schließlich Verlust der Krone und Verschwinden von der Bildfläche.

\section{Zusammenfassung}

Der Mantel, vor allem Ottokars goldgestickter Prunkmantel, hat in Grillparzers ,König Ottokar die Qualität eines Symbols (ähnlich wie Rudolfs grauer Rock). Generell kann man sagen, das die Kleidung (neben den genannten Kleidungsstücken sind es die Rüstung des Königs, der Helm des Kaisers, die Mäntel der Königinnen und die Schleife von Kunigunde) in diesem Drama, in dem das Ausziehen eines Kleidungsstücks mit dem Ausziehen des Wesens gleichgesetzt wird (vgl. Prutti 2013:315), eine wichtige Rolle spielen. Ottokars Nieder- und Untergang wird begleitet vom Ausziehen symbolisch aufgewerteter Kleidungstücke. Der König, der aus einer siegreichen Schlacht zurückkommt, betritt die Bühne in einer Rüstung, in der er wie ein Kriegsgott aussieht. Diese Assoziation ist gewollt, denn Grillparzer selbst gibt zu, im Bild des Kriegsgottes Mars den entscheidenden Impuls für die Darstellung des Böhmenkönigs gefunden zu haben (vgl. oben). Ottokar zieht die Rüstung aus und verwandelt sich sofort von einem strahlenden Sieger in einen rechthaberischen „Greis“ (als einen Greis bezeichnet ihn Kunigunde, die ihn schon ohne die Rüstung kennen lernt - vgl. KO: 430). Er hüllt sich in einen goldgestickten Mantel, dessen Pracht seine Macht verdinglichen soll, in dem sich aber auch die Kluft zwischen ihm und seinen Untertanen widerspiegelt und der sich im Laufe der Handlung immer deutlicher in ein Feigenblatt verwandelt, das die Blöße eines verunsicherten „Mannes“ (als einen bloßen Mann sieht sich Ottokar selbst, bevor er zu seinem letzten Gefecht antritt - vgl. KO:503) verdecken soll. In ebendiesem Mantel muss Ottokar auch seine größte Demütigung hinnehmen, als er vor dem einstigen Empfänger seiner Befehle, dem nunmehrigen Kaiser Rudolf, niederknien muss. Wenn er dann fluchtartig die Bühne verlässt, gleitet ihm der Mantel von den Schultern. Die Krone hält der König zwar immer noch in der Hand, aber seine Größe ist dahin und die Macht über seine Untertanen, die ihm zunehmend den Gehorsam verweigern, ist ebenfalls im Schwinden begriffen. Nach dem Verlust seiner Autorität, der sich im Herabfallen des Prunkmantels widerspiegelt, hüllt sich Ottokar in einen dunklen Mantel, in dem er wie ein Marodeur durch seine Länder zieht und dem Hohn seiner dreist gewordenen Umgebung ausgesetzt ist. Nach der letzten Schlacht, in der er nicht mehr wie ein siegessicherer Kriegsherr, sondern wie ein verunsicherter Zauderer aufgetreten ist (Ottokars Mitstreiter Füllenstein kommentiert diese Tatsache mit einem Rückgriff auf die kleidungszentrierte Bildersprache: Der König hat sein Wesen 
ausgezogen. - KO:490), liegt er nackt auf dem Boden. Die Devestitur ist zu Ende: Aus dem geharnischten Kriegsgott und dem purpurumhüllten König ist ein nackter Leichnam geworden, über den der siegreiche Kaiser seinen von Ottokar einst angestrebten Mantel ausbreitet: „Der Kaisermantel fungiert [...] als die ästhetische Verhüllung der Tatsache, dass das Devestiturdrama den mächtigen König von Böhmen auf seine abjekte Körperlichkeit reduziert hat" (Prutti 2013:319 f.). ${ }^{17}$

In Anerkennung der Tatsache, dass Rudolfs grauer Rock eine Reminiszenz an die Burschenschafter und die von ihnen getragene ,Altdeutsche Tracht“ sein dürfte, bietet sich natürlich die Frage, ob auch Ottokars monumentaler Prunkmantel eine Reminiszenz ist. Bekanntlich war nicht nur der Kriegsgott Mars, sondern auch der Franzosenkaiser Napoleon ein Vorbild für Ottokar. Grillparzer gibt diese Ähnlichkeit zu, verschweigt jedoch, dass sie die Qualität einer Wesensverwandtschaft hat. Ottokar tritt bei Grillparzer als Verkörperung des neuzeitigen Individualismus auf, dessen historischer Spitzenrepräsentant Napoleon ist (vgl. Kost 2002:132). Dem entspricht sowohl Ottokars Pochen auf die eigene herausragende Rolle bei dem Aufbau seines gewaltigen Reiches als auch sein selbstbewusstes, auf den ersten Blick widersinniges Auftreten gegenüber den Abgesandten der Reichsfürsten, die ihm die eigentlich heißbegehrte Kaiserkrone in Aussicht stellen. Statt sie mit Dank und Demut zu empfangen, befiehlt ihnen Ottokar, die Kaiserkrone zu ihm zu bringen. Er will sich überlegen, ob er die Kaiserkrone annimmt, und die (so gut wie sichere) Annahme als einen Akt des eigenen Willens präsentieren. Ottokar will auf diese Weise den Eindruck verhindern, dass er die Kaiserkrone aus den Händen der Reichsfürsten empfangen hat. Er handelt wie Napoleon, der es abgelehnt hat, die Krone aus den Händen des Papstes zu empfangen. Und ähnlich wie Napoleon hat er einen Sinn für die Macht der Bilder und ist bestrebt, seine Machtfülle mit Pomp und Prunk zu verbrämen. Ottokars Prunkmantel gewinnt die Qualität von Napoleons Purpurmantel, den der Franzosenkaiser bei seiner Krönung trug, in dem er sich mehrmals porträtieren ließ und in dem er auf dem Maifeld von 1815 eher erfolglos um die Anerkennung seiner erschütterten Herrscherautorität durch das skeptische Volk warb. Einen Nachhall dieser Szene dürfte man - Belege dafür gibt es in Grillparzers Nachlass nicht - in der Begegnung zwischen Ottokar und Rudolf finden. Der aufgedonnerte Ottokar, dessen Prunkmantel seine erschütterte Feldherrn- und Herrscherautorität verdecken soll, wirkt auf Kaumberg ebenso unangebracht und clownesk wie der im Festornat auftretende Napoleon auf dem Marsfeld. In Ottokars Selbstentkrönung und seiner Flucht von der Bühne, mit der die Begegnung der beiden Antagonisten endet, spiegelt sich schließlich - in grotesker Umkehrung - die Selbstkrönung Napoleons von 1804 wider.

\section{Literaturverzeichnis}

\section{Primärliteratur:}

KO: Grillparzer, Franz (1986): König Ottokars Glück und Ende. In: GriLlParzer, Franz: Werke in sechs Bänden. Bd. 2 (Dramen, 1817-1828). Frankfurt am Main, S. 391-510 und 830-881 (Kommentar).

\section{Sekundärliteratur:}

Castelot, André (1998): Napoleon Bonaparte. Praha.

DelPhENDAHL, Renate (1975): Grillparzer. Lüge und Wahrheit in Wort und Bild. Bern; Stuttgart.

17 Während er den toten Böhmenkönig in seinen Mantel hüllt, sagt Rudolf: So liegst du nackt und schmucklos, großer König, / Das Haupt gelegt in deines Dieners Schoß, / Und ist von deinem Prunk und Reichtum allen/Nicht eine arme Decke dir geblieben, / Als Leichentuch zu hüllen deinen Leib. / Den Kaisermantel, dem du nachgestrebt, / Ich nehm ihn ab und breit ihn über dich /[...] / Dass als ein Kaiser du begraben werdest, / Der du gestorben wie ein Bettler bist (KO:508). In Kušejs Inszenierung von 2005 fehlt die Szene der postmortalen Verhüllung des Böhmenkönigs mit dem Kaisermantel. Ottokars Prunkmantel ist jedoch deutlich durch den österreichischen Kaisermantel inspiriert, der zu Beginn der 1830er Jahre vom Hoftheaterkostümdirektor Philipp von Stubenrauch entworfen worden war und durch das 1832 entstandene Porträt des österreichischen Kaisers Franz I. von Friedrich von Amerling berühmt wurde. Diese Aufmachung macht die kaiserlichen Ambitionen des Böhmenkönigs sichtbar, verleiht ihm zugleich ein unzeitgemäßes Look und unterstreicht das Theatralische in seinem Auftritt. 
DoPPLER, Alfred (1990): Der Herrscher, ein trüber Spiegel der absoluten Ordnung: Franz Grillparzers Staatsdramen. In: DopPLER, Alfred (Hrsg.): Geschichte im Spiegel der Literatur. Aufsätze zur österreichischen Literatur des 19. und 20. Jahrhunderts. Innsbruck, S. 15-30.

DOPPLER, Alfred (1990): Die Entheroisierung des Kriegshelden: „König Ottokars Glück und Ende“. In: Doppler, Alfred (Hrsg.): Geschichte im Spiegel der Literatur. Aufsätze zur österreichischen Literatur des 19. und 20. Jahrhunderts. Innsbruck, S. 31-37.

Fournier, August (1906): Napoleon I. Eine Biographie. Dritter Band: Die Erhebung der Nationen und Napoleons Ende. Wien; Leipzig.

GrossEGGER, Elisabeth (2014): König Ottokars Glück und Ende. Identitätsbefragungen im Erinnerungsjahr 2005. In: Jahrbuch der Grillparzer-Gesellschaft, 3. Folge (Bd. 25). Wien, S. 8-27.

Kost, Jürgen (2002): Zwischen Napoleon, Metternich und habsburgischem Mythos. Überlegungen zum Gegenwartsbezug des Geschichtsdramas am Beispiel von Grillparzers „König Ottokar“. In: Jahrbuch der Grillparzer-Gesellschaft, 3. Folge (Bd. 20). Wien, S. 125-158.

LoRenz, Dagmar C. G. (1986): Grillparzer, Dichter des sozialen Konflikts. Wien; Köln; Graz.

PörnbaCHER, Karl (1970): Franz Grillparzers „König Ottokars Glück und Ende“. Erläuterungen und Dokumente. Stuttgart.

PRUTTI, Brigitte (2013): Grillparzers Welttheater: Modernität und Tradition. Bielefeld.

SAGARRA, Eda (1986): Sinnbilder der Monarchie. Herrschersymbolik und Staatsidee in Grillparzers König Ottokars Glück und Ende und Shakespeares Richard II. In: Jahrbuch der Grillparzer-Gesellschaft, 3. Folge (Bd. 16). Wien, S. 57-67.

Urbanec, Miroslav (2019): Des Kaisers grauer Rock. Zur Herausstellung des Deutschtums Kaiser Rudolfs in Franz Grillparzers Trauerspiel ,König Ottokars Glück und Ende‘. In: Acta Facultatis Philosophicae Universitatis Ostraviensis. Studia Germanistica, Nr. 25, Ostrava, S. 63-73.

\section{Internetquelle:}

THIERs, Adolphe (1865): History of the Consulate and the Empire of France Under Napoleon. Volume 5. Philadelphia. Abrufbar im Internet. URL: https://books.google.cz/books?id=41QwAQAAMAAJ\&redir_esc=y $(12.10 .2020)$. 